\title{
Digital Politics
}

\author{
Michael Bernhard and Daniel O'Neill
}

\section{The Special Section}

$\square$ apid changes in the fields of micro-electronics and data processing have transformed the world over the last thirty years. The first personal computers appeared in the mid-1970s and these started to become common in offices in the mid-1980s, before becoming an everyday necessity soon thereafter. While forms of remote communication between computers in government and in research universities began in the 1960 s, the origins of the omnipresent Internet of today only emerged in the late 1980s and early 1990s, when commercial Internet providers began to offer widespread service to firms and customers. The ramifications of these two sets of changes have been far reaching. For those of us old enough to remember, this latest iteration of the industrial revolution has fundamentally transformed the way we used to do so many things - produce, consume, wage war, and live-on a day-to day-basis. Some of the most far-reaching changes have been in politics, where new virtual social networks have transformed the public sphere. This transformation poses a whole new set of problems for the control of information and organizations in closed societies, and creates the means for new and powerful forms of informational distortion and manipulation in open ones.

In this issue we present four articles that discuss the impact of this paradigm shift on how we fight, get around, and entertain ourselves. The first two contributions address how transportation in urban areas has been disrupted by the rise of Uber. In many places it has challenged the highly regulated and profitable taxi industry, devaluing assets and displacing labor. Not only has Uber transformed urban transportation markets, creating winners (mostly the entrepreneurs who created, invested, and bet on platform companies) and losers (taxi companies and drivers), its new mode of delivering services has escaped conventional measures of government regulation and challenged local and municipal governments to find ways of coping with innovation.

The lead article, entitled "Disrupting Regulation, Regulating Disruption: The Politics of Uber in the United States," is coauthored by Ruth Berins Collier, Veena Dubal, and Christopher Carter. Their focus is not only on the alteration of the settled patterns of urban transportation markets, but on how Uber has also effectively escaped regulation by local government, state legislatures, and the courts. First, its new means of service provision escape traditional ways of regulating commerce. Second, Uber has both taken advantage of the privileged position of capital to contest regulation in the bureaucracy and the courts, and it has also selectively mobilized consumers and its own drivers to counter the grievances raised by taxi companies and drivers. Similar themes are raised in Kathleen Thelen's "Regulating Uber: The Politics of the Platform Economy in Europe and the United States." She explores Uber's impact in a more comparative perspective using evidence from the United States, Germany, and Sweden. Thelen shows how the entry of Uber into markets under different systems of regulation triggered different flashpoints in each country. These flashpoints in turn mobilized different actors, shaped somewhat different conflicts, and led to different regulatory outcomes.

The third piece in the special section has an international relations focus. In "The Politics of Attributing Blame for Cyberattacks and the Costs of Uncertainty," Marcus Schulzke notes that the difficulty in determining the origin and motives of cyberattacks makes it hard for actors to formulate appropriate responses. He notes that the problem of cybersecurity and attack attribution is largely an issue taken up by experts and politicians. He argues that it is essential to involve the citizenry in broader public discussions, lest uncertainty about the identity of the perpetrator leads to the blaming of familiar scapegoats and the cultivation of conspiracy theories. In this sense cyberattacks may pose additional costs in terms of maintaining accountability in democratic societies.

The last piece in our special section is "It's the End of the World and They Know It: How Dystopian Fiction Shapes Political Attitudes" by Calvert W. Jones and Celia Paris. You may wonder why we placed a piece on the impact of dystopian fiction in a digital politics section. First, there has been a rise in the popularity of dystopian novels, television series, and films. These would include The Hunger Games, The Maze Runner, Enders Game, The Matrix, $V$ for Vendetta, Minority Report, Divergent, Mr. Robot, and The Walking Dead, as well as reinterpretations 
of such classics as Fahrenheit 451, Westworld, The Man in the High Castle, Blade Runner, and The Handmaid's Tale. By its nature, dystopian fiction takes unsettling trends in the present and imagines what it would be like if they were extrapolated into the future. We take the huge popularity of the genre to be an indicator of the anxiety about our future in the present digital age. In many of these cautionary tales, the growing power of technology to allow us to manipulate, monitor, and control others lies at the heart of the nightmare. In addition, the stories studied here are now distributed in new ways with the streaming of online content replacing conventional print and broadcast media.

Jones and Paris argue that political scientists have chosen to ignore the impact that fiction has on the formation of political attitudes. Arguing that the best way to approach such questions is by examining different popular genres, they run a series of experiments to gauge the impact of exposure to dystopian fiction on values and attitudes. They come up with an interesting set of findings-first, that exposure makes viewers more likely to justify radical, even violent, action against unjust authority. However, despite this, viewers seem to experience no deterioration in their levels of social capital.

The importance of digital politics is also reflected in the increasing number of scholarly monographs published on the topic. In the Book Review portion of this issue, we highlight a range of such recent work in a special "Digital Politics" section.

\section{Articles}

This issue includes three additional stimulating articles. The first is a new contribution to the journal's extended engagement with the impact of the carceral state on race and politics in the United States. Michael Leo Owens and Hannah Walker take a position contrary to the current wisdom that all involuntary contact with the carceral system has negative implications for political participation. Based on a sample drawn from metropolitan Chicago, in "The Civic Voluntarism of 'Custodial Citizens': Involuntary Criminal Justice Contact, Associational Life, and Political Participation," they show that while custodial citizens are less likely to vote or to register to vote even after re-enfranchisement, those involved with civil society organizations are far more likely to participate in nonelectoral civic activity.

In "Partners in Crime: An Empirical Evaluation of the CIA Rendition, Detention, and Interrogation Program" Averell Schmidt and Kathryn Sikkink examine the impact of participation in the CIA's rendition program on human-rights protections in partner states. Rejecting a narrow functionalist logic on whether rendition programs are successful in thwarting terrorism, Schmidt and Sikkink find that in authoritarian partner states, general human-rights abuses increased with participation.
The evidence leads to the conclusion that anti-terrorist programs need to be assessed in a fashion that takes into account their broader consequences, including the welfare of citizens in partner countries.

In "Bounded Rationality without Bounded Democracy: Nudges, Democratic Citizenship, and Pathways for Building Civic Capacity," Mark Edward Button considers the possible civic consequences of state interventions that seek to influence individual behaviors in ways that produce predictable outcomes it favors. Button contends that this recent behavioral turn in public policy risks missing the importance of the personal capacities and institutional conditions necessary for democratic citizenship. However, he argues that empirical evidence drawn from the study of deliberative democracy shows how liberal societies can address the issue of "bounded rationality" while simultaneously facilitating civic virtues and upholding individual liberty in the context of a pluralistic society.

\section{Reflections}

We have three provocative Reflections as well in this issue. In the discipline we are keenly aware of issues of gender, and as in many parts of American life the \#MeToo movement has had an important impact on leading universities such as Harvard, ${ }^{1}$ and highly visible journals such as the American Journal of Political Science. ${ }^{2}$ APSA commissioned a task force to study sexual harassment at its annual meeting, and it issued an influential report on this issue in 2018. While the report found that a majority of members had not experienced sexual harassment at the annual meeting, a substantial minority of women $(42 \%)$ and a smaller minority of men (22\%) had experienced some form of negative behavior of this type. ${ }^{3}$ We asked Virginia Sapiro, one of the coauthors of the report, whose long and distinguished career includes a number of important contributions in the area of gender politics, to reflect on the question of harassment.

In "Sexual Harassment: Performances of Gender, Sexuality, and Power," Sapiro draws on her background in political behavior and democratic theory to explain sexual harassment's intractability through a framework that focuses on its embeddedness in subordinating structures. After discussing the problem through the lenses of public opinion, law, public policy, and performative theory, she proposes a normative standard of "anti-subordination" to identify and respond to issues of harassment in a consistent and consequential fashion.

The second reflection contributes to our understanding of the current wave of democratic backsliding plaguing a number of world regions, none more perhaps than Central Europe. In "Democratic Backsliding and Academic Freedom in Hungary," Zsolt Enyedi, a Professor of Political Science and the Pro-Rector for Hungarian Affairs at Central European University (CEU), explores the impact of democratic backsliding on academic freedom 
in Viktor Orbán's Hungary. The text not only provides a first-hand account of what has transpired at CEU, but discusses how the defense of academic freedom is a defense of freedom more generally, and how universities and academics need to step up and play a critical role in fighting for it. The issue of democratic erosion is also considered in the Review section, with a wide-ranging symposium on Steven Levitsky and Daniel Ziblatt's recent influential book, How Democracies Die, which became a New York Times best seller. Contributions to the symposium come from Sheri Berman, Valerie Bunce, William Connolly, Katherine Cramer, Christopher Sebastian Parker, and Aníbal Pérez-Liñán.

Our last reflection is less contemporary, but no less important. Recently, comparative historical work on the origins of democracy has reevaluated the role of religion and its development in that process. In "The Ecclesiastical Roots of Representation and Consent," Jørgen Møller argues that discussions of the emergence of representative institutions in the medieval period neglect the emergence of representation and consensual rule in the Catholic Church. Such practices later diffused into the secular realm. This insight sheds further light on why representative forms of government first arose and spread throughout the Latin West.

\section{Final Thoughts}

Issue 16(4) concludes our first calendar year at the helm of the journal. It has been a highly educative experience for us on the state of the discipline and its practitioners. It really feels like a privilege. The volume for 2019 is shaping up in interesting ways. Issue 17(1) will feature Kathleen Thelen's presidential address and a special section on qualitative methods. That will be followed in 17(2) by our special issue on "Trump: Causes and Consequences" and a special section on "Celebrity and Politics," guest-edited by board member Samantha Majic, will follow in the second half of the year.

\section{Notes}

1 Bartlett and Gluckman 2018.

2 Cunningham 2018.

3 Sapiro and Campbell 2018, 1.

\section{References}

Bartlett, Tom and Nell Gluckman. 2018. "She Left Harvard. He Got to Stay." The Chronicle of Higher Education, February 27. Available at https://www. chronicle.com/interactives/harvard-harassment, accessed August 12, 2018.

Cunningham, Rachel. 2018. "MSU Professor Investigated for Sexual Misconduct, Resigns from Journal." The Michigan Daily, May 2. Available at https://www. michigandaily.com/section/academics/msu-professorand-um-researcher-accused-sexual-misconduct-resignsjournal, accessed August 12, 2018.

Sapiro, Virginia and David Campbell. 2018. Draft Report on the 2017 APSA Survey on Sexual Harassment at Annual Meetings. Committee on Professional Ethics, Rights, and Freedoms. American Political Science Association. Available at https://www.apsanet.org/ Portals/54/journals/APSA\%20EthicsCommitteeSexual $\% 20$ Harassment $\% 20$ Report\%20Final.pdf?ver $=2018$ 01-04-132931-660, accessed August 12, 2018. 


\section{Statement of Mission and Procedures}

Perspectives on Politics seeks to provide a space for broad and synthetic discussion within the political science profession and between the profession and the broader scholarly and reading publics. Such discussion necessarily draws on and contributes to the scholarship published in the more specialized journals that dominate our discipline. At the same time, Perspectives seeks to promote a complementary form of broad public discussion and synergistic understanding within the profession that isessential toadvancing scholarship and promoting academic community.

Perspectives seeks to nurture a political science public sphere, publicizing important scholarly topics, ideas, and innovations, linking scholarly authors and readers, and promoting broad reflexive discussion among political scientists about the work that we do and why this work matters.

Perspectives publishes work in a number of formats that mirror the ways that political scientists actually write:

Research articles: As a top-tier journal of political science, Perspectives accepts scholarly research article submissions and publishes the very best submissions that make it through our double-blind system of peer review and revision. The only thing that differentiates Perspectives research articles from other peer-reviewed articles at top journals is that we focus our attention only on work that in some way bridges subfield and methodological divides, and tries to address a broad readership of political scientists about matters of consequence. This typically means that the excellent articles we publish have been extensively revised in sustained dialogue with the editor-me-to address not simply questions of scholarship but questions of intellectual breadth and readability.

"Reflections" are more reflexive, provocative, or programmatic essays that address important political science questions in interesting ways but are not necessarily as systematic and focused as research articles. These essays often originate as research article submissions, though sometimes they derive from proposals developed in consultation with the editor in chief. Unlike research articles, these essays are not evaluated according to a strict, doubleblind peer review process. But they are typically vetted informally with editorial board members or other colleagues, and they are always subjected to critical assessment and careful line-editing by the editor and editorial staff.

Scholarly symposia, critical book dialogues, book review essays, and conventional book reviews are developed and commissioned by the editor in chief, based on authorial queries and ideas, editorial board suggestions, and staff conversations.

Everything published in Perspectives is carefully vetted and edited. Given our distinctive mission, we work hard to use our range of formats to organize interesting conversations about important issues and events, and to call attention to certain broad themes beyond our profession's normal subfield categories.

For further details on writing formats and submission guidelines, see our website at http://www.apsanet.org/ perspectives/ 